\title{
利用非共价构象锁定设计小分子受体材料
}

庄林

武汉大学化学与分子科学学院, 武汉 430072

\section{Designing Electron Acceptor via Noncovalently Conformational Locking}

\section{ZHUANG Lin}

College of Chemistry and Molecular Sciences, Wuhan University, Wuhan 430072, P. R. China.

Email: lzhuang@whu.edu.cn

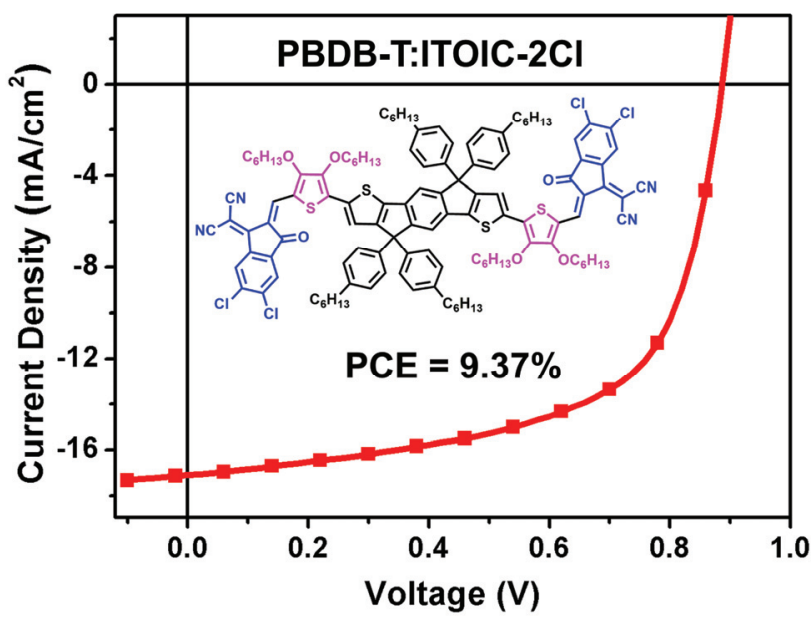

电子受体分子结构及太阳能电池电流密度-电压 $(J-V)$ 曲线

聚合物太阳能电池(PSC)具有质轻, 成本低, 可 通过溶液加工的方法大面积制备柔性器件等优 点, 受到广泛关注 ${ }^{1-3}$ 。目前, 体异质结(BHJ)结构 的 PSC 主要采用共轭高分子给体材料和受体材料 共混制备光电活性层。2015 年, 占肖卫课题组首 先报道了一类非富勒烯的高效率的稠环电子受体 (FREAs $)^{4,5}$ 。这类受体具有化学结构易修饰, 能级 易调控以及跟给体聚合物吸收互补等显著优点, 受 到研究者们的青睐。近 3 年来, 基于 FREAs 构建 的电池的效率不断被刷新, 目前已经超过 $14 \%$ 。

FREAs 通常采用受体-给体-受体(A-D-A)型结 构, 受体材料的分子能级和吸收光谱主要通过对 给体单元, 受体单元以及给受体单元二者之间的 联结方式的有效调控来实现。
北京师范大学薄志山、李翠红等人, 在前期工 作中, 提出通过分子内的非共价作用设计受体材 料可以简单有效地扩大受体分子的共轭长度, 拓 宽吸收光谱, 增强电子传输, 从而极大地提高了器 件的光伏性能 8 。运用这种策略, 他们合成了一种 新的 A-D-A 型受体材料(ITOIC-2Cl), 在给体单元 和受体单元间引入 3,4-二己氧基噻吩作桥。受体分 子在溶液中具有较大的溶解度, 而在薄膜中可以 通过 $\mathrm{S} \cdots \mathrm{O}$ 和 $\mathrm{O} \cdots \mathrm{H}$ 等弱相互作用在分子内形成 非共价键构象锁促进分子的平面性。此外, 他们在 端基上修饰成本低的 $\mathrm{Cl}$ 原子, 通过增加端基的缺 电子性增强分子内的电荷转移 ${ }^{9}$ 。在两者的协同 作用下, ITOIC-2Cl 的光谱吸收拓宽到近红外 区, 有利于获得宽的光谱响应。基于该受体材料 
的 PSC, 实现了 $9.37 \%$ 的光电转换效率, 其开路 电压 $\left(V_{\mathrm{oc}}\right)$ 为 $0.886 \mathrm{~V}$, 短路电流 $\left(J_{\mathrm{sc}}\right)$ 为 17.09 $\mathrm{mA} \cdot \mathrm{cm}^{-2}$, 填充因子 $(\mathrm{FF})$ 为 $61.8 \%$ 。以上实验结 果已在物理化学学报上在线发表 (doi: 10.3866/PKU.WHXB201805161) ${ }^{10}$, 该工作为我 们提供了一种设计高效率的非富勒烯稠环电子 受体的简单有效的策略。

\section{References}

(1) Li, Y. F. Acc. Chem. Res. 2012, 45 (5), 723. doi:10.1021/ar2002446

(2) Yu, G.; Gao, J.; Hummelen, J. C.; Wudl, F.; Heeger, A. J. Science 1995, 270 (5243), 1789. doi: 10.1126/science.270.5243.1789

(3) Krebs, F. C. Sol. Energy Mater. Sol. Cells 2009, 93 (4), 393. doi: 10.1016/j.solmat.2008.12.008

(4) Lin, Y. Z.; Zhang, Z. G.; Bai, H. T.; Wang, J. Y.; Yao, Y. H.; Li, Y. F.; Zhu, D. B.; Zhan, X. W. Energy Environ. Sci. 2015, 8 (2), 610. doi: $10.1039 / \mathrm{c} 4 \mathrm{ee} 03424 \mathrm{~d}$

(5) Lin, Y. Z.; Wang, J. Y.; Zhang, Z. G.; Bai, H. T.; Li, Y. F.; Zhu, D. B.;
Zhan, X. W. Adv. Mater. 2015, 27 (7), 1170. doi: 10.1002/adma.201404317

(6) Zhang, S.; Qin, Y.; Zhu, J.; Hou, J. Adv. Mater. 2018, in press. doi: 10.1002/adma.201800868

(7) Li, S. S.; Ye, L.; Zhao, W, C.; Yan, H. P.; Yang, B.; Liu, D. L.; Li, W. N.; Ade, H.; Hou, J. H. J. Am. Chem. Soc. 2018, 140 (23), 7159. doi: $10.1021 /$ jacs.8b02695

(8) Liu, Y. H.; Zhang, Z.; Feng, S. Y.; Li, M.; Wu, L. L.; Hou, R.; Xu, X. J.; Chen, X. B.; Bo, Z. S. J. Am. Chem. Soc. 2017, 139 (9), 3356. doi: $10.1021 /$ jacs.7b00566

(9) Yao, H. F.; Cui, Y.; Yu, R. N.; Gao, B. W.; Zhang, H.; Hou, J. H. Angew. Chem. Int. Ed. 2017, 56 (11), 3045. doi: 10.1002/anie.201610944

(10) Feng, S. Y.; Lu, H.; Liu, Z. K.; Liu, Y. H.; Li, C. H.; Bo, Z. S. Acta Phys. -Chim. Sin. 2019, 35 (4), 355. [冯诗语, 路皓, 刘泽坤, 刘亚 辉, 李翠红, 薄志山. 物理化学学报, 2019, 35 (4), 355.] doi: 10.3866/PKU.WHXB201805161 